\title{
The effect of farmed trout on cardiovascular risk markers in healthy men
}

\author{
Jesper Hallund ${ }^{1}$, Birgitte Overgaard Madsen ${ }^{1}$, Susanne H. Bügel ${ }^{1}$, Charlotte Jacobsen ${ }^{2}$, Jette Jakobsen ${ }^{3}$, \\ Henrik Krarup ${ }^{4}$, Jørgen Holm ${ }^{5}$, Henrik H. Nielsen ${ }^{2}$ and Lotte Lauritzen ${ }^{1 *}$ \\ ${ }^{1}$ Department of Human Nutrition, Faculty of Life Sciences, University of Copenhagen, Rolighedsvej 30, DK-1958 Frederiksberg C, \\ Denmark \\ ${ }^{2}$ DTU-Aqua, Technical University of Denmark, Lyngby, Denmark \\ ${ }^{3}$ National Food Institute, Technical University of Denmark, S $\phi b o r g$, Denmark \\ ${ }^{4}$ Department of Clinical Biochemistry, Aalborg Hospital, Arhus University Hospital, Aalborg, Denmark \\ ${ }^{5}$ BioMar A/S, Brande, Denmark
}

(Received 4 February 2010 - Revised 25 May 2010 - Accepted 26 May 2010 - First published online 2 July 2010)

Increased intake of marine long-chain $n$-3 PUFA ( $n$-3 LCPUFA) may decrease the risk of CVD and reduce mortality by lowering serum TAG and blood pressure (BP). Furthermore, $n$-3 LCPUFA may affect novel CVD risk markers related to inflammation and vascular function. The objective of the present study was to examine the effect of farmed trout on novel and traditional CVD risk markers in healthy men, and to evaluate whether this was affected by the aquacultural feed regime. We performed a parallel, 8-week intervention study in which sixty-eight healthy male volunteers were randomised to consume either a daily meal with $150 \mathrm{~g}$ farmed trout raised on either marine or vegetable-based feed, or a reference meal containing $150 \mathrm{~g}$ chicken. Twenty-four hour BP, pulse wave velocity, augmentation index, fatty acid composition of erythrocyte (RBC), and concentrations of TAG, HDL-cholesterol, LDL-cholesterol, glucose, insulin, C-reactive protein (CRP) and other markers of inflammation were measured at weeks 0 and 8 . RBC content of total $n$-3 LCPUFA, both EPA and DHA, was significantly higher among men consuming trout raised on marine feed compared with men consuming the vegetable-fed trout or chicken. The three intervention groups did not differ significantly with respect to any of the other outcome variables, although there were trends towards associations between the changes in RBC $n-3$ LCPUFA and those in BP and CRP. In the present study, we conclude that we could not confirm the fish oil-induced reduction in CVD risk markers after daily consumption of trout with high or low $n-3$ LCPUFA content. However, trout raised on vegetable-based feed had less pronounced impact on RBC $n-3$ LCPUFA status.

n-3 PUFA: Vascular function: Blood pressure: Plasma lipid profile

A large number of prospective studies have shown that regular fish consumption is related to a lower risk of CVD, such as stroke ${ }^{(1)}$ and $\mathrm{CHD}^{(2)}$. The health-promoting effect of fish has been ascribed to the long-chain $n-3$ PUFA ( $n-3$ LCPUFA), EPA and DHA. A meta-analysis of the randomised intervention trials performed showed that $n-3$ LCPUFA may reduce mortality in patients with $\mathrm{CHD}^{(3)}$. n-3 LCPUFA may protect against CVD by lowering serum $\mathrm{TAG}^{(4)}$, blood pressure $(\mathrm{BP})^{(5)}$ and heart rate ${ }^{(6)}$, as has been shown in randomised trials with fish oil supplementation.

In addition, $n$-3 LCPUFA may affect novel CVD risk markers related to inflammation and vascular function. Chronic low-grade inflammation and increased adhesiveness for circulating leucocytes to vascular endothelial cells is believed to play a key role in the process leading to atherosclerosis and $\mathrm{CVD}^{(7)}$. Increased plasma concentrations of the acute-phase reactant C-reactive protein (CRP) have been shown to be associated with $\mathrm{CVD}^{(8)}$, and circulating concentrations of adhesion molecules are considered to indicate a pro-inflammatory state in the vasculature and to be predictive of CVD risk ${ }^{(9)}$. A number of studies have examined the effect of $n-3$ LCPUFA supplementation on inflammatory markers in healthy subjects ${ }^{(10-15)}$. The majority of these studies have shown that $n$-3 LCPUFA supplementation has little or no effect on CRP, whereas the effect on cell adhesion molecules is more complex and uncertain. Vascular function may also play a central role in the development, progression and clinical manifestations of atherosclerosis, and a number of studies indicate that $n$-3 LCPUFA may positively improve vascular function ${ }^{(16-22)}$, but there are some studies that do not find such an effect ${ }^{(23)}$.

Only few well-designed randomised intervention trails have examined the effect of increased fish intake on CVD risk markers in healthy and high-risk subjects ${ }^{(24-31)}$, but the results are inconclusive. Fish rich in $n$-3 LCPUFA have been shown to reduce serum TAG in some studies ${ }^{(24,25,27,28)}$,

Abbreviations: AIx, augmentation index; BP, blood pressure; CRP, C-reactive protein; HDL-C, HDL-cholesterol; $n$-3 LCPUFA, long-chain $n$-3 PUFA; PWV, pulse wave velocity; RBC, erythrocyte; sVCAM, soluble vascular cell adhesion molecule.

* Corresponding author: L. Lauritzen, fax +45 3533 2483, email 11@life.ku.dk 
but not in all studies ${ }^{(26,30)}$, and the effect on inflammation is inconclusive $^{(27-29,31)}$. Additional studies have focused on the effect of other fish components, such as fish protein and vitamin $\mathrm{D}$, on CVD risk markers in animals and human subjects. These studies suggest that fish protein may improve $\mathrm{BP}^{(32,33)}$ and insulin sensitivity ${ }^{(34)}$, decrease plasma $\mathrm{CRP}^{(35)}$ and modulate lipoprotein metabolism ${ }^{(36,37)}$. Vitamin $\mathrm{D}$ has been shown to improve CVD risk markers such as endothelial function ${ }^{(38)}$.

In Denmark, farmed fish contribute increasingly to the overall fish consumption, due to the reduced availability of wild fish and an increasing demand. The most important fish farmed in Denmark is the rainbow trout (Oncorhynchus mykiss). However, the aquaculture sector is facing major challenges due to limited access to marine raw material resources. Therefore, vegetable oil and protein are introduced as alternative ingredients in feed for fish farming. Such change in feed composition may influence the human health effect of the trout. Presumably, the content of $n-3$ LCPUFA will decrease whereas that of $n-6$ PUFA will rise, as has been shown in other fish species depending on the vegetable oil used $^{(28)}$. However, only a single study has examined clinical effects of fish raised on different types of feeds in CVD patients $^{(28)}$. The overall objective of the present study is to examine the effect of intake of farmed trout on novel and traditional CVD risk markers in healthy men, and to evaluate whether the fish feed composition (100\% marine or vegetablebased feed) had any effect on the measured parameters.

\section{Subjects and methods}

\section{Subjects}

The present study was conducted according to the guidelines laid down in the Declaration of Helsinki, and all procedures involving human subjects were approved by the Local Research Ethical Committee of Copenhagen and Frederiksberg (H-KF 325441). Written informed consent was obtained from all the subjects after they had received oral and written information about the study. We recruited healthy adult men from Copenhagen and the surrounding areas by advertising in the local media. Men, who were interested in the study, contacted the principal investigator, who interviewed them by telephone using a detailed screening questionnaire. Those who met the inclusion criteria were invited to take part in a physical examination. Eligible participants were apparenty healthy males aged 40-70 years with no history of CVD, inflammatory disease, diabetes, or other significant medical history, no regular use of medication known to affect the outcome measures, e.g. anti-inflammatories, hypertension medication or statins. In addition, participants had to be non-smokers or smokers of $<7$ cigarettes/week, had to have a $\mathrm{BP}<160 / 100 \mathrm{mmHg}$ and a BMI between 20 and $30 \mathrm{~kg} / \mathrm{m}^{2}$, were not allowed to take fish oil supplements, had to follow a weight-reducing diet, had to be regular blood donors, or had to be trained athletes or heavy exercisers. Those who used vitamin and/or mineral supplements before the study were instructed to continue during the study period. Six participants used multivitamin supplements throughout the study (one in the marine trout group, two in the vegetable trout group and three in the chicken group). One participant from the marine trout group smoked an average of three cigarettes per week, and one participant in the chicken group smoked eight cigarettes per week.

\section{Study design}

We performed a randomised, parallel, 8-week intervention study in adult males. The volunteers were randomised to consume either a daily meal with $150 \mathrm{~g}$ farmed trout fillet either raised on a pure marine diet (marine trout) or on a pure vegetable diet (vegetable trout), or a reference meal containing $150 \mathrm{~g}$ chicken.

A weekly meal plan was provided, which included seven different meals, i.e. fresh salad, lasagne, steamed fillet with carry sauce, steamed fillet with spicy potatoes, thai meat balls, steamed fillet with tomato sauce and meat balls with bacon. The trout and chicken meals were identical in all respects other than the main ingredient being trout or chicken, and for the chicken meals, the addition of $3.5 \mathrm{~g}$ rapeseed oil to provide the same amount of fat per meal. The fatty acid composition of the fish and chicken fillets is shown in Table 1. The daily intake of $150 \mathrm{~g}$ marine trout, vegetable trout or chicken provided an amount of $3.4 \mathrm{~g} / \mathrm{d}(2.0$ and $0.9 \mathrm{~g} / \mathrm{d}$ of DHA and EPA, respectively), 0.8 and $0.2 \mathrm{~g} / \mathrm{d}$

Table 1. Fatty acid composition of the fish and chicken fillets

(Mean values and standard deviations, weight percentages from three separate determinations)

\begin{tabular}{|c|c|c|c|c|c|c|}
\hline \multirow[b]{2}{*}{ Variables } & \multicolumn{2}{|c|}{ Marine trout } & \multicolumn{2}{|c|}{ Vegetable trout } & \multicolumn{2}{|c|}{ Chicken* } \\
\hline & Mean & SD & Mean & SD & Mean & SD \\
\hline Total SFA (\%) & $25 \cdot 0$ & 0.2 & $15 \cdot 2$ & 0.3 & $20 \cdot 8$ & 1.4 \\
\hline Total MUFA (\%) & $32 \cdot 0$ & $1 \cdot 0$ & $51 \cdot 8$ & 1.0 & $47 \cdot 2$ & $1 \cdot 8$ \\
\hline Total PUFA (\%) & $35 \cdot 7$ & $1 \cdot 0$ & $30 \cdot 3$ & 0.8 & $32 \cdot 1$ & 2.9 \\
\hline Linoleic acid (C18:2n-6) (\%) & $3 \cdot 7$ & 0.1 & $15 \cdot 1$ & 0.2 & $22 \cdot 1$ & $1 \cdot 7$ \\
\hline Arachidonic acid (C20:4n-6) (\%) & 0.7 & 0.04 & 0.8 & 0.04 & $1 \cdot 8$ & 0.3 \\
\hline$\alpha$-Linolenic acid (C18:3n-3) (\%) & $1 \cdot 2$ & 0.02 & 3.5 & $0 \cdot 1$ & $3 \cdot 2$ & 0.4 \\
\hline C18: $4 n-3$ & 1.5 & 0.01 & 0.9 & 0.03 & - & - \\
\hline $\mathrm{C} 20: 4 n-3$ & $1 \cdot 1$ & 0.02 & 0.3 & 0.01 & - & - \\
\hline EPA (C20 : 5n-3) (\%) & $6 \cdot 9$ & 0.2 & $1 \cdot 3$ & $0 \cdot 1$ & 0.3 & 0.04 \\
\hline Docosapentaenoic acid (C22:5n-3) (\%) & $2 \cdot 6$ & 0.04 & 0.5 & 0.04 & 0.8 & $0 \cdot 1$ \\
\hline $\mathrm{DHA}(\mathrm{C} 22: 6 n-3)(\%)$ & $16 \cdot 3$ & 0.7 & $5 \cdot 1$ & 0.8 & 0.5 & $0 \cdot 1$ \\
\hline$n-6 / n-3$ PUFA & $0 \cdot 16$ & $0 \cdot 01$ & 1.48 & 0.12 & 3.33 & $0 \cdot 25$ \\
\hline
\end{tabular}

* Values for chicken are given with the inclusion of $3.5 \mathrm{ml}$ rapeseed oil per $150 \mathrm{~g}$ fillet. 
n-3 LCPUFA, respectively. The vitamin $\mathrm{D}_{3}$ and 25-hydroxy vitamin $\mathrm{D}_{3}$ contents of the marine trout were 0.62 and $<0 \cdot 1 \mu \mathrm{g} / 100 \mathrm{~g}$, respectively, and the content of both vitamin $\mathrm{D}_{3}$ and 25-hydroxy vitamin $\mathrm{D}_{3}$ of the vegetable trout was $<0 \cdot 1 \mu \mathrm{g} / 100 \mathrm{~g}$, and that of the chicken was $<0 \cdot 1$ and $0 \cdot 1 \mu \mathrm{g} / 100 \mathrm{~g}$, respectively. The average energy and macronutrient content of trout and chicken meals were similar. Mean meal energy was $1856 \mathrm{~kJ}$, and the contribution of macronutrients was protein $37 \mathrm{~g}$, carbohydrate $26 \mathrm{~g}$ and fat $22 \mathrm{~g}$. The volunteers visited the department twice a week during lunch or dinner throughout the study period (at the end of the intervention period, this was reduced to once a week for some of the subjects). At these visits, they consumed the freshly prepared daily meal (the salad meal and the steamed fillet with spicy potatoes), and received frozen meals until their next visit. The five handout meals were produced in a single batch and were frozen at $-30^{\circ} \mathrm{C}$ until use. The volunteers were instructed to consume their habitual diets throughout the study period, but were instructed to avoid consumption of any seafood. Furthermore, the volunteers were instructed to consume one study meal per day as lunch or dinner, and to keep daily records of meal consumption and well-being in a study diary. Compliance was assessed using the study diaries, as well as using an analysis of erythrocyte (RBC) fatty acid composition.

The volunteers visited the department for two examinations during the study: at the beginning of the study (week 0) and after the intervention period (week 8). During the visits, we measured height (only at week 0), body weight, waist and hip circumference, $24 \mathrm{~h} \mathrm{BP}$, pulse wave velocity (PWV) and augmentation index (AIx). Furthermore, we collected a $12 \mathrm{~h}$ fasting blood sample for the assessment of fatty acid composition of RBC, plasma concentrations of TAG, HDLcholesterol (HDL-C), LDL-cholesterol, and serum concentration of CRP, IL-6, soluble vascular cell adhesion molecule (sVCAM)-1, insulin and glucose. Blood samples were collected during the morning after $15 \mathrm{~min}$ supine rest (a total of $90 \mathrm{ml}$ blood during the entire study). The volunteers consumed a standardised low-fat meal providing a maximum of $15 \mathrm{~g}$ fat the evening before the collection of blood. The volunteers kept a $3 \mathrm{~d}$ weighed food record for 1 week before the study and during the last week of the intervention period to estimate habitual dietary intake. Energy and macronutrient intake were calculated using the Dankost 2000 dietary assessment software (National Food Agency, Herlev, Denmark).

\section{Laboratory measurements}

The fatty acid composition and vitamin D content of the trout and chicken were determined. The meat $(50 \mathrm{~g})$ was minced, and $10 \mathrm{~g}$ (in duplicate) were used for the determination of lipid content. Muscle lipids were extracted using a chloroform-methanol mixture $(1: 1, \mathrm{v} / \mathrm{v})$ according to the protocol of Bligh \& Dyer ${ }^{(39)}$. The lipids were transmethylated with $\mathrm{B}$ trifluoride in methanolic $\mathrm{NaOH}^{(40)}$. The resulting fatty acid methyl esters were dissolved in $n$-heptane, and separated on a HP 5890 gas chromatograph (Hewlett-Packard, Palo Alto, CA, USA) equipped with a flame ionisation detector and an Omegawax 320 fused silica capillary column $(30 \mathrm{~m} \times 0.32 \mathrm{~mm}$ internal diameter $\times 0.25 \mu \mathrm{m})($ Supelco, Belafonte, PA, USA). The initial oven temperature was $160^{\circ} \mathrm{C}$, immediately raised by $3^{\circ} \mathrm{C} / \mathrm{min}$ to $200^{\circ} \mathrm{C}$, held for $1 \mathrm{~min}$, further raised by $3^{\circ} \mathrm{C} /$ min to $220^{\circ} \mathrm{C}$ and held for $12 \mathrm{~min}$. Peaks from $14: 0$ to $22: 6(n-3)$ were identified from retention times of commercial standards (Nu-Chek-Prep, Elysian, MN, USA). Each fatty acid was quantified by calculating its peak area relative to the total peak area. Vitamin $\mathrm{D}_{3}$ and 25-hydroxy vitamin $\mathrm{D}_{3}$ in the fish and the chicken were determined as described previously $^{(41,42)}$. Briefly, the internal standards of vitamin $\mathrm{D}_{2}$ and 25-hydroxy vitamin $\mathrm{D}_{2}$ were added to the samples, and all vitamers were saponified with ethanolic $\mathrm{KOH}$. After extraction of the unsaponifiable matter with diethyl etherpetroleum ether $(1: 1, \mathrm{v} / \mathrm{v})$, the purification of the extract included a solid-phase and a preparative HPLC step with silica and amino columns. The final separation, detection and quantification of the vitamers were performed by a HPLC system (Waters, Milford, MA, USA) equipped with reversed-phase columns, diode array detector and UV detectors. The detection and quantification levels were 0.02 and $0 \cdot 1 \mu \mathrm{g} / 100 \mathrm{~g}$, respectively, for both of the vitamin D metabolites.

Fatty acid composition of RBC was determined on lipid from thawed RBC from heparinised blood samples, which were haemolysed in redistilled water and extracted by the Folch procedure ${ }^{(43)}$, transmethylated with $\mathrm{B}$ trifluoride in methanolic $\mathrm{NaOH}$, and extracted by heptane. Fatty acid methyl esters from 12:0 to 22:6 (n-3) were separated by GLC, as described previously ${ }^{(4)}$. The fatty acid compositions of all RBC samples were determined in duplicate, and the results were expressed as the percentage area of each fatty acid relative to fatty acid peaks together. Plasma vitamin D was measured with DiaSorin LIAISON ${ }^{\circledR}$ 25-hydroxy vitamin D TOTAL (DiaSori, Inc., Stillwater, OK, USA). The LIAISON $^{\circledR} 25$-hydroxy vitamin D TOTAL assay is a direct competitive chemiluminescence immunoassay for quantitative measurement of total 25-hydroxy vitamin $\mathrm{D}$ in serum or plasma $^{(45)}$. We found that precision ranges $(\mathrm{CV}, \mathrm{CV} \%)$ were as stated by the manufacturer, within-run $3 \cdot 2-8 \cdot 1 \%$ and total precision $6 \cdot 9-12.7 \%$.

The analyses of plasma CVD risk markers were performed by standard methods. The plasma lipid profile was determined in blood drawn into a $7 \mathrm{ml}$ EDTA tube (no. 367655; Becton Dickinson, Meylan Cedex, France), which was centrifuged at $2000 \mathrm{~g}$ for $10 \mathrm{~min}$ at $20^{\circ} \mathrm{C}$ and stored at $-80^{\circ} \mathrm{C}$ until analysis. total cholesterol, HDL-C and TAG were measured on a Cobas Mira + analyser (Roche Diagnostic, Basel, Switzerland) with enzymatic kits from Roche (Roche Diagnostic cholesterol oxidase-p-aminophenazone, HDL-C-plus 2nd generation, and glycerol phosphate oxidase- $p$-aminophenazone, respectively). The LDL-cholesterol concentrations were calculated using the Friedewald formula ${ }^{(46)}$. The intra- and inter-assay CV\% were 0.9 and $1.6 \%, 2.6$ and $4.0 \%$, and 0.9 and $3.2 \%$ for total cholesterol, HDL-C and TAG, respectively. Glucose was measured in blood drawn into a $2 \mathrm{ml} \mathrm{NaFI}$ tube (Becton Dickinson no. 368520), centrifuged at $2200 \mathrm{~g}$ for $15 \mathrm{~min}$ at $4^{\circ} \mathrm{C}$ and stored at $-80^{\circ} \mathrm{C}$ until analysis. Glucose was measured with the use of an enzymatic endpoint method (Hexokinase) (Gluco-quant Glucose/HK; Roche Diagnostics) using an ABX Pentra 400 chemistry analyser (ABX Pentra, Horiba ABX, Montpellier, France); intra-assay $\mathrm{CV}$ was $1.9 \%$. Blood drawn into a $10 \mathrm{ml}$ tube with no additives (Becton Dickinson no. 368430) was used for the analysis of high-sensitive CRP, IL-6, sVCAM-1 and insulin. It was 
centrifuged at $2200 \mathrm{~g}$ for $15 \mathrm{~min}$ at $4^{\circ} \mathrm{C}$ and stored at $-80^{\circ} \mathrm{C}$. CRP was measured with a chemiluminescent immunometric assay (Diagnostic Products Corporation, Los Angeles, CA, USA) using a Pentra 400 analyser (Horiba Diagnostics). Intra- and inter-assay CV for CRP were 3.6 and $2.3 \%$, respectively. IL-6 and sVCAM-1 concentrations were determined using human IL-6 (Quantikine HS600; R\&D Systems Europe Limited, Abingdon, UK) and sVCAM-1 (Parameter BBE3; R\&D Systems Europe Limited) immunoassay kits. Intra- and inter-assay CV were 4.2 and $3.1 \%$, and 5.7 and $6.0 \%$ for IL-6 and sVCAM-1, respectively. Insulin was measured on an Immulite 1000 analyser by solid-phase, two-site chemiluminescent immunometric assay (Immulite/ immuliter 1000 insulin; Diagnostic Products Corporation). Intra- and inter-assay CV for insulin were 2.8 and $4.9 \%$, respectively. Insulin resistance was estimated using the homeostatic assessment model and calculated according to the formula ${ }^{(47)}$ :

\section{Homeostatic assessment model}

$$
\begin{aligned}
& =\text { fasting plasma insulin }(\mu \mathrm{U} / \mathrm{ml}) \\
& \times \text { fasting plasma glucose }(\mathrm{mmol} / \mathrm{l}) / 22 \cdot 5 \text {. }
\end{aligned}
$$

\section{Pulse wave analysis and pulse wave velocity measurements}

All the pulse wave measurements (AIx and PWV) were performed using an applanation tonometer (SPT-301B; Millar, Houston, TX, USA) and the SphygmoCor ${ }^{\circledR}$ hardware and software (version 7.1; Atcor Medical, Sydney, Australia). The brachial BP was assessed by oscillometry (UA-787 Digital BP monitor; A\&D Medical, Tokyo, Japan) using the average of the last two out of three BP recordings. The method of AIx and PWV measurements has been described in detail elsewhere ${ }^{(48)}$. AIx is a surrogate measure of arterial stiffness, defined as the proportion of the central pulse pressure that is due to the late systolic peak and the reflected pulse wave. Briefly, AIx was estimated using an algorithm, the 'generalised transfer function' determined by a pulse wave analysis based on a mean of ten radial pulse wave forms and a brachial BP. Aortic PWV was determined as the difference in travel time of the pulse wave between the femoral and carotid artery. The time difference was determined by relating both signals to the start of the pulse wave determined from an electrocardiogram. The surface distance between the two recording sites was then measured, thus allowing PWV to be determined (velocity $=$ distance/time).

\section{Ambulatory blood pressure monitoring}

All volunteers underwent $24 \mathrm{~h}$ ambulatory BP monitoring using the Spacelabs 90217-15Q ambulatory BP monitor (Spacelab, Inc., Washington, DC, USA). The appropriate sized cuff was placed on the non-dominant arm, and measurements were made every $15 \mathrm{~min}$ between 07.00 and 23.00 hours, and every $30 \mathrm{~min}$ during the night. Mean BP was calculated from the readings during the entire $24 \mathrm{~h}$ period.

\section{Power calculations}

We used the method of least standardised difference to calculate the number of participants needed in the present study. The study was designed to demonstrate a difference in plasma TAG between the marine trout and the control (chicken) groups. The inclusion of twenty men/group gave the study enough power $(90 \%)$ to detect a significant difference $(P<0.01)$ of $0.28 \mathrm{mmol} / 1 \quad(20 \%)$ plasma TAG. This is the mean difference observed after the consumption of $0 \cdot 4-4 \mathrm{~g} n-3 \mathrm{LCPUFA} / \mathrm{d}$ in patients with CVD according to the recent Cochrane meta-analysis ${ }^{(49)}$. The standard deviation of mean change in plasma TAG was set to $0 \cdot 22$ as earlier reported ${ }^{(50)}$.

\section{Statistical analysis}

Data describing the characteristics of the volunteers are summarised as the means and standard deviations. Data on the outcome of the study are expressed either as means with their standard errors or as the median and 25th, 75th percentiles. Data were analysed in Statistical Analysis System 9.1 (SAS Institute ${ }^{\circledR}$, Inc., Cary, NC, USA) using a mixed model ANOVA with treatment as fixed factors, subjects as random factor and the baseline measurements as a covariate. The covariate $\times$ treatment interaction was included to test for varying slopes/interactions. Data on total $\operatorname{RBC} n-3$ LCPUFA, plasma TAG and serum CRP were log transformed to obtain normally distributed residuals. Differences were considered significant when $P<0 \cdot 05$. We performed the bivariate associations between the changes in RBC $n-3$ LCPUFA and in outcome variables by Pearson's correlation. The following mixed model analysis initially included the baseline measurement and changes in dietary variables (total energy intake, macronutrient composition (energy from protein and fat/ carbohydrate), intake of fibres and fat quality (ratio of PUFA to SFA and relative content of MUFA)). The dietary variables were excluded one by one based on their $P$-value until a final model was found that included only those dietary parameters that had a $P$-value $<0 \cdot 1$ at baseline and the RBC $n$-3 LCPUFA variable.

\section{Results}

Seventy-five male volunteers were recruited for the study, and sixty-eight of these volunteers completed the study according to the protocol. One participant dropped out for personal reasons, two were dropped out due to illness during the study period, and four were dropped out because they did not like the study meals. The three groups were comparable with respect to baseline characteristics of the volunteers with no significant differences in age, anthropometric measurements, estimated energy and macronutrient intake (Table 2). In addition, there were no significant differences between the three groups in any of the baseline measurements of the outcome variables assessed in the study (data not shown). During the intervention period, body weight $(P=0.314)$ or waist to hip ratio $(P=0.093)$ did not differ between the three intervention groups. Furthermore, there were no significant differences between the groups in the estimated intake of energy $(P=0.151)$, fat $(P=0.244)$, protein $(P=0.757)$, carbohydrate $(P=0 \cdot 220)$ and total fibre $(P=0.471)$.

Compliance assessed using study diaries showed that the consumption of study meals during the intervention period was $99 \%$. Furthermore, changes in the fatty acid composition 
Table 2. Baseline characteristics of the men participating in each of the three diet groups (Mean values and standard deviations)

\begin{tabular}{|c|c|c|c|c|c|c|c|}
\hline \multirow[b]{2}{*}{ Variables } & \multicolumn{2}{|c|}{ Marine trout $(n 23)$} & \multicolumn{2}{|c|}{ Vegetable trout $(n 23)$} & \multicolumn{2}{|c|}{ Chicken ( $n$ 22) } & \multirow[b]{2}{*}{$P^{*}$} \\
\hline & Mean & SD & Mean & SD & Mean & SD & \\
\hline Age (years) & 52 & 9 & 54 & 7 & 53 & 9 & 0.643 \\
\hline Height $(\mathrm{cm})$ & 178.5 & $5 \cdot 6$ & $179 \cdot 0$ & $4 \cdot 3$ & 181.9 & $5 \cdot 7$ & 0.076 \\
\hline Weight (kg) & $77 \cdot 4$ & $9 \cdot 1$ & $80 \cdot 1$ & $8 \cdot 0$ & $82 \cdot 6$ & $8 \cdot 3$ & 0.130 \\
\hline BMI $\left(\mathrm{kg} / \mathrm{m}^{2}\right)$ & $24 \cdot 2$ & $2 \cdot 3$ & $25 \cdot 0$ & $2 \cdot 4$ & $25 \cdot 0$ & $2 \cdot 1$ & 0.455 \\
\hline Waist (cm) & 91.5 & $8 \cdot 0$ & $94 \cdot 0$ & $8 \cdot 6$ & 93.0 & $8 \cdot 0$ & 0.593 \\
\hline Waist:hip ratio & 0.93 & 0.05 & 0.94 & 0.06 & 0.93 & 0.07 & 0.826 \\
\hline Energy $(\mathrm{MJ} / \mathrm{d})$ & $10 \cdot 1$ & 0.5 & $10 \cdot 2$ & 0.6 & $10 \cdot 4$ & 0.5 & 0.934 \\
\hline Fat (\% of energy) & 30 & 1 & 31 & 1 & 33 & 1 & 0.155 \\
\hline Protein (\% of energy) & 15 & 1 & 16 & 1 & 16 & 1 & 0.607 \\
\hline Carbohydrate (\% of energy) & 49 & 1 & 48 & 1 & 47 & 1 & 0.517 \\
\hline Fibre $(g / d)$ & 30 & 3 & 28 & 3 & 28 & 2 & 0.745 \\
\hline
\end{tabular}

${ }^{*} P$-values for the difference between the groups (ANOVA).

of RBC from the beginning to the end of the intervention period show good agreement between the intake of $n-3$ LCPUFA and the incorporation of these fatty acids, thus indicating good compliance to the study protocol (Table 3). The men consuming the marine trout and vegetable trout had a significant higher RBC concentration of total $n-3$ LCPUFA, EPA and DHA at the end of the intervention compared with the men consuming chicken. Furthermore, the men in the marine trout intervention group had a significant higher RBC concentration of total $n-3$ LCPUFA, EPA and DHA compared with the men in the vegetable trout intervention group. There was a similar, but reciprocal, change in total $n$-6 PUFA and linoleic acid. The mean 25-hydroxy vitamin $\mathrm{D}$ status of the subjects at the beginning of the intervention period was 47 (SD 23) $\mathrm{mmol} / \mathrm{l}$, and the status decreased with $33(20-44) \%$ for the subjects, who participated in the intervention during the fall, and increased with $31(-5-64) \%$ for the subjects, who participated during spring. However, there were no significant differences between the intervention groups $(P=0.442)$.

There were no significant differences in plasma total cholesterol, TAG, LDL-cholesterol and HDL-C concentrations between the three groups at the end of the intervention period (Table 4). The mean changes in TAG from baseline to week 8 was $-0.14(\mathrm{SD} 0.35),-0.08(\mathrm{SD} 0.51)$ and -0.13 (SD 0.42 ) $\mathrm{mmol} / \mathrm{l}$ for the marine trout, vegetable trout and chicken intervention groups, respectively. In order to control for the effect of changes in the carbohydrate intake during the intervention periods, changes in carbohydrate were included in the statistical model as a controlling factor, but this did not reveal any significant difference between the changes in plasma TAG concentration in the three groups $(P=0.935)$. In addition, there was no significant difference in the changes in serum concentrations of CRP, IL-6, sVCAM-1, insulin and glucose or in homeostatic assessment model between the three groups during the intervention period. Furthermore, there were no significant differences in the change in PWV, AIx, heart rate, or in the systolic or diastolic BP between the three groups during the intervention period (Table 5).

The incorporation of $n-3$ LCPUFA in RBC tended to be associated with a reduction in diastolic blood pressure and an increase in CRP, most pronounced when expressed as the $n-3$ to $n$-6 PUFA ratio (Pearson $r 0 \cdot 225, P=0 \cdot 074, n$ 64) and EPA ( $r 0.289, P=0 \cdot 019, n 64)$, respectively. The association for BP was improved, when the model was adjusted for changes in diet. The overall model $r^{2}$ for the change in diastolic blood pressure after adjustment for change in relative intake of MUFA was 0.697 ( $P=0.018$ for RBC $n-6 / n-3$ PUFA), and

Table 3. Fatty acid composition of erythrocytes in the trout or chicken group at baseline and 8-week intervention period (Mean values with their standard errors)

\begin{tabular}{|c|c|c|c|c|c|c|c|c|c|c|c|c|c|}
\hline \multirow[b]{3}{*}{ Variables } & \multicolumn{4}{|c|}{ Marine trout } & \multicolumn{4}{|c|}{ Vegetable trout } & \multicolumn{4}{|c|}{ Chicken } & \multirow[b]{3}{*}{$P^{\star}$} \\
\hline & \multicolumn{2}{|c|}{ Week 0} & \multicolumn{2}{|c|}{ Week 8} & \multicolumn{2}{|c|}{ Week 0} & \multicolumn{2}{|c|}{ Week 8} & \multicolumn{2}{|c|}{ Week 0} & \multicolumn{2}{|c|}{ Week 8} & \\
\hline & Mean & SEM & Mean & SEM & Mean & SEM & Mean & SEM & Mean & SEM & Mean & SEM & \\
\hline Total SFA (\%) & 40.5 & 0.2 & 39.8 & 0.3 & $40 \cdot 8$ & 0.4 & $40 \cdot 0$ & 0.4 & 40.7 & 0.4 & $40 \cdot 8$ & 0.4 & 0.0682 \\
\hline Total MUFA (\%) & 19.9 & 0.3 & $18 \cdot 9$ & 0.3 & $19 \cdot 3$ & 0.3 & $19 \cdot 0$ & 0.3 & $19 \cdot 8$ & 0.2 & $19 \cdot 8$ & 0.4 & 0.0696 \\
\hline Total PUFA $(n-6)(\%)$ & $28 \cdot 1$ & 0.5 & $25 \cdot 7^{\mathrm{c}}$ & 0.4 & $27 \cdot 5$ & 0.3 & $27 \cdot 6^{\mathrm{b}}$ & 0.4 & $28 \cdot 1$ & 0.6 & $29 \cdot 1^{a}$ & 0.4 & $<0.0001$ \\
\hline Linoleic acid $(C 18: 2 n-6)(\%)$ & 12.5 & 0.3 & $10 \cdot 9^{c}$ & 0.3 & $12 \cdot 2$ & 0.4 & $11.5^{\mathrm{b}}$ & 0.3 & $12 \cdot 0$ & 0.4 & $12 \cdot 5^{\mathrm{a}}$ & 0.3 & $<0.0001$ \\
\hline AA $(C 20: 4 n-6)(\%)$ & $10 \cdot 8$ & 0.3 & $10 \cdot 8$ & 0.3 & $10 \cdot 8$ & 0.3 & 11.4 & 0.4 & 11.5 & 0.4 & $11 \cdot 7$ & 0.4 & 0.2716 \\
\hline Total PUFA $(n-3)(\%)$ & 9.3 & 0.6 & $13 \cdot 7^{\mathrm{a}}$ & 0.6 & 9.2 & 0.3 & $10 \cdot 2^{\mathrm{b}}$ & 0.3 & 9.5 & 0.5 & $8 \cdot 3^{\mathrm{c}}$ & 0.4 & $<0.0001$ \\
\hline EPA $(C 20: 5 n-3)(\%)$ & 0.9 & 0.1 & $2 \cdot 5^{\mathrm{a}}$ & 0.2 & 1.0 & 0.1 & $1 \cdot 1^{\mathrm{b}}$ & 0.1 & $1 \cdot 1$ & 0.2 & $0.7^{\mathrm{c}}$ & 0.1 & $<0.0001$ \\
\hline $\mathrm{DHA}(\mathrm{C} 22: 6 n-3)(\%)$ & 4.2 & 0.2 & $7 \cdot 0^{\mathrm{a}}$ & 0.2 & 4.6 & 0.2 & $5 \cdot 8^{\mathrm{b}}$ & 0.2 & 5.0 & 0.3 & $4 \cdot 2^{c}$ & 0.3 & $<0.0001$ \\
\hline
\end{tabular}

AA, arachidonic acid.

a,b,c Mean values with unlike superscript letters differ for $n$-3 PUFA with $P<0.0001$ and for $n-6$ PUFA with $P<0.01$.

${ }^{\star} P$-values for the treatment effect analysed using a mixed model ANOVA. 
Table 4. Plasma lipid concentrations and serum concentrations of circulation markers of inflammation of the trout or chicken group at the beginning and end of the intervention period

(Mean values with their standard errors)

\begin{tabular}{|c|c|c|c|c|c|c|c|c|c|c|c|c|c|}
\hline \multirow[b]{3}{*}{ Variables } & \multicolumn{4}{|c|}{ Marine trout } & \multicolumn{4}{|c|}{ Vegetable trout } & \multicolumn{4}{|c|}{ Chicken } & \multirow[b]{3}{*}{$P^{*}$} \\
\hline & \multicolumn{2}{|c|}{ Week 0} & \multicolumn{2}{|c|}{ Week 8} & \multicolumn{2}{|c|}{ Week 0} & \multicolumn{2}{|c|}{ Week 8} & \multicolumn{2}{|c|}{ Week 0} & \multicolumn{2}{|c|}{ Week 8} & \\
\hline & Mean & SEM & Mean & SEM & Mean & SEM & Mean & SEM & Mean & SEM & Mean & SEM & \\
\hline TAG $(\mathrm{mmol} / \mathrm{l})$ & 1.02 & 0.08 & 0.88 & 0.09 & 1.28 & 0.13 & $1 \cdot 20$ & 0.18 & $1 \cdot 11$ & 0.11 & 0.99 & 0.10 & 0.702 \\
\hline $\mathrm{TC}(\mathrm{mmol} / \mathrm{l})$ & 4.74 & 0.17 & 5.06 & 0.23 & 5.05 & $0 \cdot 19$ & $5 \cdot 18$ & 0.25 & 4.67 & 0.13 & $4 \cdot 74$ & 0.13 & 0.475 \\
\hline LDL-C (mmol/l) & $2 \cdot 89$ & 0.15 & 3.05 & 0.19 & $3 \cdot 17$ & 0.17 & 3.17 & 0.20 & $2 \cdot 83$ & 0.09 & 2.93 & 0.13 & 0.565 \\
\hline $\mathrm{HDL}-\mathrm{C}(\mathrm{mmol} / \mathrm{l})$ & 1.20 & 0.05 & 1.23 & 0.04 & $1 \cdot 15$ & 0.04 & 1.19 & 0.05 & $1 \cdot 18$ & 0.05 & $1 \cdot 15$ & 0.22 & 0.296 \\
\hline Glucose (mmol/l) & $5 \cdot 62$ & 0.35 & $5 \cdot 66$ & 0.43 & 5.65 & 0.47 & $5 \cdot 68$ & 0.47 & $5 \cdot 64$ & 0.60 & $5 \cdot 61$ & 0.53 & 0.826 \\
\hline Insulin (pmol/l) & $32 \cdot 9$ & $18 \cdot 0$ & 39.7 & $19 \cdot 9$ & $35 \cdot 6$ & $20 \cdot 9$ & $36 \cdot 4$ & $16 \cdot 8$ & 34.4 & $16 \cdot 3$ & $37 \cdot 7$ & $19 \cdot 1$ & 0.261 \\
\hline HOMA-IR & 1.39 & 0.80 & 1.68 & 0.88 & 1.54 & 1.01 & 1.56 & 0.78 & 1.47 & 0.80 & 1.60 & 0.92 & 0.312 \\
\hline CRP (mg/l) & 0.68 & 0.22 & $1 \cdot 23$ & 0.41 & 0.87 & 0.29 & 0.95 & 0.22 & 0.53 & $0 \cdot 11$ & 0.68 & 0.14 & 0.482 \\
\hline IL-6 (ng/l) & $1 \cdot 10$ & 0.12 & 1.17 & 0.17 & 1.14 & 0.14 & 1.28 & 0.25 & 1.24 & $0 \cdot 16$ & 1.33 & 0.20 & 0.430 \\
\hline sVCAM-1 (ng/ml) & 644 & 38 & 637 & 37 & 707 & 41 & 707 & 40 & 647 & 28 & 630 & 28 & 0.437 \\
\hline
\end{tabular}

TC, total cholesterol; LDL-C, LDL cholesterol: HDL-C, HDL cholesterol; HOMA-IR, homeostatic model assessment-insulin resistance; CRP, C-reactive protein, sVCAM-1, soluble vascular cell adhesion molecule-1.

${ }^{\star} P$-values for the treatment effect analysed using a mixed model ANOVA.

the $r^{2}$ for systolic blood pressure after adjustment for change in relative intake of dietary fibre and protein was 0.595 $(P=0.037$ for RBC $n-6 / n-3$ PUFA, both $n$ 64).

\section{Discussion}

The results from the present study showed a significantly higher increase in RBC $n$-3 LCPUFA status following the intake of traditionally marine-fed trout compared with a daily intake of trout raised on vegetable-based feed after 2 months. These differences reflected differences in the $n-3$ LCPUFA content of the trout meat. However, the intake of both types of trout resulted in a significant increase in the RBC $n$-3 LCPUFA concentrations compared with the intake of chicken or baseline values. In contrast to what we expected, the intake of marine trout was not associated with any reduction in plasma TAG or clear beneficial effects in any of the other CVD risk markers that we assessed - although some trends were observed for CRP and BP. It is therefore not possible to make any firm conclusion with respect to the effect of the aquacultural feed regime on the health-promoting effect of the fish from the results of the present study.
Some previous studies have reported beneficial effects of fish interventions on classical CVD risk markers such as plasma TAG, HDL-C and BP, in healthy lean and overweight subjects $^{(24-27,51,52)}$. Some of these studies compared the effect of fish with no intervention or the effect of vegetable oil capsules ${ }^{(25,51,52)}$. Some made comparisons between fatty and lean fish ${ }^{(27,52)}$, and only two of the studies made a comparison with a meat $\operatorname{diet}^{(24,26)}$. The results from the trials are difficult to compare as the effects will depend on health status of the included subjects, dose, duration and $n-3$ LCPUFA composition of the fish. The subjects in the Moore study varied in weight loss across groups, which made the evaluation of the results difficult. The most well-controlled studies appear to be the ones by Lindqvist et al. ${ }^{(2)}$ and Gunnarsdottir et $a l .{ }^{(52)}$, who tried to keep a constant diet and macronutrient composition. The length of their studies were comparable to that of the present study, but they both had more subjects per group and supplied only about half the dose of $n-3$ LCPUFA (as herring or salmon, respectively) as we did in our marine trout group, and their subjects were somewhat younger but overweight. None of these two studies found any marked differences in plasma lipid profile or BP between the fatty fish diets and their pork/chicken or cod diet.

Table 5. Pulse wave velocity (PWV), pulse wave analysis, heart rate (HR) and blood pressure of the trout or chicken group at the beginning and end of the intervention period

(Mean values with their standard errors)

\begin{tabular}{|c|c|c|c|c|c|c|c|c|c|c|c|c|c|}
\hline \multirow[b]{3}{*}{ Variables } & \multicolumn{4}{|c|}{ Marine trout } & \multicolumn{4}{|c|}{ Vegetable trout } & \multicolumn{4}{|c|}{ Chicken } & \multirow[b]{3}{*}{$P^{\star}$} \\
\hline & \multicolumn{2}{|c|}{ Week 0} & \multicolumn{2}{|c|}{ Week 8} & \multicolumn{2}{|c|}{ Week 0} & \multicolumn{2}{|c|}{ Week 8} & \multicolumn{2}{|c|}{ Week 0} & \multicolumn{2}{|c|}{ Week 8} & \\
\hline & Mean & SEM & Mean & SEM & Mean & SEM & Mean & SEM & Mean & SEM & Mean & SEM & \\
\hline $\mathrm{PWV}(\mathrm{m} / \mathrm{s})$ & 7.52 & 0.19 & $7 \cdot 57$ & 0.19 & $7 \cdot 62$ & 0.26 & 7.51 & 0.18 & $7 \cdot 37$ & 0.26 & 7.50 & 0.24 & 0.682 \\
\hline Alx (\%) & $19 \cdot 52$ & 2.04 & $19 \cdot 00$ & $2 \cdot 22$ & $19 \cdot 48$ & $2 \cdot 24$ & $19 \cdot 46$ & $2 \cdot 28$ & $19 \cdot 00$ & $2 \cdot 52$ & $17 \cdot 23$ & $2 \cdot 45$ & 0.575 \\
\hline Alx75 (\%) & 9.74 & 2.06 & $9 \cdot 76$ & $2 \cdot 20$ & $10 \cdot 54$ & $2 \cdot 43$ & $10 \cdot 04$ & $2 \cdot 72$ & 8.73 & $2 \cdot 64$ & 7.95 & $2 \cdot 42$ & 0.872 \\
\hline HR (beats per minute) & 55 & 1 & 56 & 2 & 54 & 2 & 55 & 2 & 54 & 1 & 56 & 1 & 0.576 \\
\hline BPsys (mmHg) & 121 & 2 & 119 & 2 & 123 & 2 & 121 & 2 & 123 & 2 & 123 & 2 & 0.197 \\
\hline BPdia $(\mathrm{mmHg})$ & 77 & 1 & 75 & 1 & 77 & 2 & 76 & 1 & 77 & 2 & 78 & 2 & 0.155 \\
\hline
\end{tabular}

Alx, augmentation index; BPsys, systolic blood pressure; BPdia, diastolic blood pressure.

${ }^{\star} P$-values for the treatment effect analysed using a mixed model ANOVA. 
Randomised interventions with $n-3$ LCPUFA from fish oil show a consistent reduction in plasma $\mathrm{TAG}^{(4)}$. A first choice of possible explanatory factors for the missing effect of $n-3$ LCPUFA from marine trout on plasma TAG in the present study would be the dose and specific type of $n$-3 LCPUFA, the healthiness of the subjects and the power. However, we have previously reported a significant reduction in plasma TAG after a similar $n-3$ LCPUFA dose in a study with sixty-six healthy young men ${ }^{(10)}$. Furthermore, a number of studies have shown that $n$-3 LCPUFA are incorporated just as effective from fish as from fish oil provided that intake is similar both in dose of $n-3$ LCPUFA and in frequency ${ }^{(53,54)}$. The power would in theory have been greater in a crossover design like the studies by Lindquist et al. ${ }^{(26)}$ and Lara et $a l .{ }^{(51)}$, but the risk of carryover effects in studies with $n-3$ LCPUFA would be a problem in such a design. Our study was based on a power calculation, but the recruited subjects were more heterogeneous than expected. The observed SD on the mean change in TAG during the intervention was $0.43 \mathrm{mmol} / \mathrm{l}$ compared with $0.22 \mathrm{mmol} / \mathrm{l}$, which was what our power calculation was based on. Another plausible explanation could be the choice of chicken as control, since chicken had a relatively high content of PUFA. The present results were also in agreement with the not so marked effects in the Lindqvist et al. ${ }^{(26)}$ study that used chicken/pork as control. Furthermore, the Danish chicken appears to have a high content of $n-3$ PUFA, which resulted in an intake of $0.2 \mathrm{~g} / \mathrm{d}$ of $n-3$ LCPUFA. With respect to the clinical effect of $n-3$ LCPUFA on CVD mortality, this appears to reach a maximum at an intake of about $0.3 \mathrm{~g} / \mathrm{d}^{(55)}$. Furthermore, there may have been differences in the diet of the groups that we did not pick up with our dietary registrations, possibly a difference in the intake of carbohydrate that could potentially counterbalance the effect of $n$-3 LCPUFA on plasma TAG, as a high carbohydrate intake has been shown to increase plasma $\mathrm{TAG}^{(56)}$. Our statistical analysis did not indicate that this would be the case, and the dietary data did not indicate any such differences between the groups. However, such dietary data may not be accurate enough, and a full dietary intervention is needed in order to avoid unintended dietary changes that could confound the effects. Many previous studies have shown a beneficial effect on BP, which we also could not confirm. However, the BP-lowering effect is most pronounced in elderly hypertensive subjects ${ }^{(5)}$. We excluded the subjects who had a treatment demanding hypertension, therefore our subjects were all more or less normotensive, but all were elderly, and their CVD risk profile reflects their age (BMI was a bit on the overweight side, total cholesterol was about $5 \mathrm{mmol} / \mathrm{l}$, glucose was also about $5 \mathrm{mmol} / \mathrm{l}$ and homeostatic model assessment was well above 1). Furthermore, we used $24 \mathrm{~h}$ ambulatory BP determinations, which provide a more sensitive and accurate measurement compared with the oscillometrically determined BP. The randomisation process did not result in any significant differences between the three groups at baseline, but there was an unfortunate tendency towards a more healthy CVD risk profile in the marine trout group that to some extent could have modified the effect of the $n$-3 LCPUFA intake.

Since no effect of marine-fed trout was detected, it is not possible to draw any clear conclusions as to the effect of the aquacultural feed. We did not expect in our power calculation to see a significant difference between the two trout groups, but rather expected a dose-response in the reduction in plasma TAG, chicken, vegetable-fed trout, marine-fed trout groups. In accordance with our hypothesis, there was a significant difference in the RBC $n$-3 LCPUFA content between the two trout groups. A number of controlled studies have shown that increased consumption of fish with a high $n-3$ LCPUFA content reduces serum $\mathrm{TAG}^{(24,28,30,57)}$, whereas other studies that used fish species with a low content of $n$-3 LCPUFA have reported no changes in $\mathrm{TAG}^{(30,58)}$. Such results support the hypothesis that the $n-3$ LCPUFA content of fish is a major determinant of the health effects, which was also indicated in the present study by significant or near significant associations between the changes in RBC $n-3$ LCPUFA and BP plus CRP in the present study. Like the present study, a recent study showed that changing the feed from fish oil to rapeseed oil in salmon fish farming produced fillets with a lower content of $n-3$ LCPUFA $^{(28)}$. In that study, CVD patients consuming the tailor-made salmon fillets with the high content of n-3 LCPUFA of marine origin had lower concentration of CVD risk markers such as serum TAG, sVCAM-1 and IL-6 when compared with the patients eating the salmon fillets with the low content of $n-3$ LCPUFA raised on vegetable feed $^{(28)}$. The present study and other studies $^{(59)}$ indicate that fish and n-3 LCPUFA affect also novel inflammation-related parameters. Again, since no effect of the marine-fed trout was observed on the classical CVD risk markers in the present study, we cannot draw any conclusion from the present results with respect to the lack of effect on the novel CVD risk markers. Some studies have observed beneficial effects of $n-3$ LCPUFA on inflammation-related clinical diseases in the absence of significant effects on immune markers of inflammation $^{(59)}$.

To our surprise, the changes in vitamin D status in the volunteers did not differ significantly between the three dietary groups. However, the marine-fed trout in our study had $<1$ $\mu \mathrm{g}$ vitamin $\mathrm{D} / 100 \mathrm{~g}$, which was only slightly higher than in trouts raised on vegetable feed and the chicken. This could be due to low vitamin $\mathrm{D}$ content in the feed, as observed previously in salmons fed a low vitamin D feed as first feeding, but not so if the vitamin D-deficient feed was fed for the last 4 months of breeding ${ }^{(60,61)}$. The vitamin $\mathrm{D}$ content of the feeds was not measured in the present study, but similar BioMAR feeds have previously been shown to contain the recommended amounts of vitamin $\mathrm{D}$ for trouts ( $\mathrm{J}$ Holm, unpublished results). However, other studies have previously found that farmed salmon only contained $25 \%$ of vitamin D compared with wild salmon ${ }^{(62)}$. The reason for the difference in vitamin $\mathrm{D}$ in farmed and wild fish is unknown. Trout is regarded as a fatty fish and as such should contain $7-8 \mu \mathrm{g}$ vitamin $\mathrm{D} / 100 \mathrm{~g}^{(63)}$. Intake of trout with this level of vitamin D would give an intake of approximately $12 \mu \mathrm{g}$ vitamin $\mathrm{D}$, which would be expected to result in an increase in vitamin D status of $24 \mathrm{nmol} / 1^{(64)}$. This again should have prevented the decrease in vitamin D status during the fall and should have given rise to a more pronounced increase during spring. With the increasing amounts of farmed fish on the market, it is essential to investigate in more detail why farmed fish have lower contents of vitamin D and how this may be increased, as it might otherwise have effects on human health. 


\section{Conclusion}

In this fish intervention study, we could not confirm the previous results, mainly from fish oil intervention trials, which have shown a beneficial effect of an increased $n-3$ LCPUFA intake on CVD risk markers. This may be due to a more heterogeneous response in diet interventions compared with pharmacological interventions with oil capsules, lack of power or the health profile of the subjects. Since no significant differences were found on CVD risk markers between the diet groups, we could not distinguish between the health effects of a traditionally grown trout and that of a trout raised on vegetable feed. However, the vegetable feed resulted in a decrease in the $n$-3 LCPUFA content of both the trout itself and the subjects who consumed the trout, which would indicate potentially less health effect. Thus, in this respect, the trout raised on vegetable feed may be equivalent to a lean type of fish.

\section{Acknowledgements}

The present study was funded by the Danish Council for Strategic Research. The experiment was initiated by L. L., S. H. B., H. H. N. and J. H. who provided the fish. The trial was performed by J. H. and B. O. M. under the supervision of L. L., C. J., J. J. and H. K. were responsible for some of the laboratory analysis. L. L. and J. H. performed the statistical analysis and drafted the paper. The other authors commented on the manuscript and wrote sections on their specific expertise. All the authors read and approved the final manuscript. None of the authors has any conflicts of interest.

\section{References}

1. He K, Song YQ, Daviglus ML, et al. (2004) Fish consumption and incidence of stroke - a meta-analysis of cohort studies. Stroke 35, 1538-1542.

2. He K, Song YQ, Daviglus ML, et al. (2004) Accumulated evidence on fish consumption and coronary heart disease mortality - a meta-analysis of cohort studies. Circulation 109, 2705-2711.

3. Leon H, Shibata MC, Sivakumaran S, et al. (2008) Effect of fish oil on arrhythmias and mortality: systematic review. BMJ 337, a2931.

4. Harris WS (1997) n-3 Fatty acids and serum lipoproteins: human studies. Am J Clin Nutr 65, S1645-S1654.

5. Geleijnse JM, Giltay EJ, Grobbee DE, et al. (2002) Blood pressure response to fish oil supplementation: metaregression analysis of randomized trials. J Hypertens 20, 1493-1499.

6. Mozaffarian D, Geelen A, Brouwer IA, et al. (2005) Effect of fish oil on heart rate in humans - a meta-analysis of randomized controlled trials. Circulation 112, 1945-1952.

7. Ross R (1999) Mechanisms of disease: atherosclerosis - an inflammatory disease. $N$ Engl J Med 340, 115-126.

8. Ridker PM, Rifai N, Rose L, et al. (2002) Comparison of C-reactive protein and low-density lipoprotein cholesterol levels in the prediction of first cardiovascular events. $N$ Engl $J$ Med 347, 1557-1565.

9. Hwang SJ, Ballantyne CM, Sharrett AR, et al. (1997) Circulating adhesion molecules VCAM-1, ICAM-1, and E-selectin in carotid atherosclerosis and incident coronary heart disease cases - the Atherosclerosis Risk in Communities (ARIC) study. Circulation 96, 4219-4225.
10. Damsgaard CT, Frøkiær H, Andersen AD, et al. (2008) Fish oil in combination with high or low intakes of linoleic acid lowers plasma triacylglycerols but does not affect other cardiovascular risk markers in healthy men. J Nutr 138, 1061-1066.

11. Thies F, Miles EA, Nebe von Caron G, et al. (2001) Influence of dietary supplementation with long-chain $n-3$ or $n-6$ polyunsaturated fatty acids on blood inflammatory cell populations and functions and on plasma soluble adhesion molecules in healthy adults. Lipids 36, 1183-1193.

12. Geelen A, Brouwer IA, Schouten EG, et al. (2004) Intake of $n-3$ fatty acids from fish does not lower serum concentrations of C-reactive protein in healthy subjects. Eur J Clin Nutr 58, 1440-1442.

13. Madsen T, Christensen JH, Blom M, et al. (2003) The effect of dietary $n-3$ fatty acids on serum concentrations of C-reactive protein: a dose-response study. Br J Nutr 89, 517-522.

14. Eschen O, Christensen JH, De Caterina R, et al. (2004) Soluble adhesion molecules in healthy subjects: a dose-response study using n-3 fatty acids. Nutr Metab Cardiovasc Dis 14, $180-185$.

15. Fujioka S, Hamazaki K, Itomura M, et al. (2006) The effects of eicosapentaenoic acid-fortified food on inflammatory markers in healthy subjects - a randomized, placebo-controlled, doubleblind study. J Nutr Sci Vitaminol 52, 261-265.

16. McVeigh GE, Brennan GM, Cohn JN, et al. (1994) Fish oil improves arterial compliance in non-insulin-dependent diabetes mellitus. Arterioscler Thromb Vasc Biol 14, 1425-1429.

17. Nestel P, Shige H, Pomeroy S, et al. (2002) The $n-3$ fatty acids eicosapentaenoic acid and docosahexaenoic acid increase systemic arterial compliance in humans. Am J Clin Nutr 76, 326-330.

18. Khan F, Elherik K, Bolton-Smith C, et al. (2003) The effects of dietary fatty acid supplementation on endothelial function and vascular tone in healthy subjects. Cardiovasc Res 59, 955-962.

19. Mita T, Watada H, Ogihara T, et al. (2007) Eicosapentaenoic acid reduces the progression of carotid intima-media thickness in patients with type 2 diabetes. Atherosclerosis 191, $162-167$

20. Hjerkinn EM, Abdelnoor M, Breivik L, et al. (2006) Effect of diet or very long chain $\omega-3$ fatty acids on progression of atherosclerosis, evaluated by carotid plaques, intima-media thickness and by pulse wave propagation in elderly men with hypercholesterolaemia. Eur J Cardiovasc Prev Rehabil 13, 325-333.

21. Schiano V, Laurenzano E, Brevetti G, et al. (2008) Omega-3 polyunsaturated fatty acid in peripheral arterial disease: effect on lipid pattern, disease severity, inflammation profile, and endothelial function. Clin Nutr 27, 241-247.

22. Goodfellow J, Bellamy MF, Ramsey MW, et al. (2000) Dietary supplementation with marine omega-3 fatty acids improve systemic large artery endothelial function in subjects with hypercholesterolemia. J Am Coll Cardiol 35, 265-270.

23. Murphy KJ, Meyer BJ, Mori TA, et al. (2007) Impact of foods enriched with $n$-3 long-chain polyunsaturated fatty acids on erythrocyte $n-3$ levels and cardiovascular risk factors. $\mathrm{BrJ}$ Nutr 97, 749-757.

24. van Houwelingen R, Zevenbergen H, Groot P, et al. (1990) Dietary fish effects on serum lipids and apolipoproteins: a controlled study. Am J Clin Nutr 51, 393-398.

25. Mori TA, Vandongen R, Beilin LJ, et al. (1994) Effects of varying dietary fat, fish, and fish oils on blood-lipids in a randomized controlled trial in men at risk of heart disease. Am J Clin Nutr 59, 1060-1068.

26. Lindqvist HM, Langkilde AM, Undeland I, et al. (2009) Herring (Clupea harengus) intake influences lipoproteins but not inflammatory and oxidation markers in overweight men. $\mathrm{Br} J$ Nutr 101, 383-390. 
27. Moore CS, Bryant SP, Mishra GD, et al. (2006) Oily fish reduces plasma triacylglycerols: a primary prevention study in overweight men and women. Nutrition 22, 1012-1024.

28. Seierstad SL, Seljeflot I, Johansen O, et al. (2005) Dietary intake of differently fed salmon: the influence on markers of human atherosclerosis. Eur J Clin Invest 35, 52-59.

29. Paulo MC, Andrade AM, Andrade ML, et al. (2008) Influence of $n-3$ polyunsaturated fatty acids on soluble cellular adhesion molecules as biomarkers of cardiovascular risk in young healthy subjects. Nutr Metab Cardiovasc Dis 18, 664-670.

30. Gerhard GT, Patton BD, Lindquist SA, et al. (1991) Comparison of three species of dietary fish - effects on serum concentrations of low-density-lipoprotein cholesterol and apolipoprotein in normotriglyceridemic subjects. Am J Clin Nutr 54, 334-349.

31. Meydani SN, Lichtenstein AH, Cornwall S, et al. (1993) Immunological effects of national cholesterol education panel step-2 diets with and without fish-derived $n-3$ fatty acid enrichment. J Clin Invest 92, 105-113.

32. Ait-Yahia D, Madani S, Prost J, et al. (2005) Fish protein improves blood pressure, but alters HDL2 and HDL3 composition and tissue lipoprotein lipase activities in spontaneously hypertensive rats. Eur J Nutr 44, 10-17.

33. Ait-Yahia D, Madani S, Savelli JL, et al. (2003) Dietary fish protein lowers blood pressure and alters tissue polyunsaturated fatty acid composition in spontaneously hypertensive rats. Nutrition 19, 342-346.

34. Ouellet V, Marois J, Weisnagel SJ, et al. (2007) Dietary cod protein improves insulin sensitivity in insulin-resistant men and women. Diabetes Care 30, 2816-2821.

35. Ouellet V, Weisnagel SJ, Marois J, et al. (2008) Dietary cod protein reduces plasma $\mathrm{C}$-reactive protein in insulin-resistant men and women. J Nutr 138, 2386-2391.

36. Shukla A, Bettzieche A, Hirche F, et al. (2006) Dietary fish protein alters blood lipid concentrations and hepatic genes involved in cholesterol homeostasis in the rat model. $\mathrm{Br} \mathrm{J}$ Nutr 96, 674-682.

37. Bergeron N, Deshaies Y \& Jacques H (1992) Dietary fish-protein modulates high-density-lipoprotein cholesterol and lipoprotein-lipase activity in rabbits. $J$ Nutr 122, 1731-1737.

38. Sugden JA, Davies JI, Witham MD, et al. (2008) Vitamin D improves endothelial function in patients with type 2 diabetes mellitus and low vitamin D levels. Diabetic Med 25, 320-325.

39. Bligh EG \& Dyer WJ (1957) A rapid method of total lipid extraction and purification. Can J Biochem Physiol 37, 911-917.

40. Hamilton S, Hamilton RJ \& Sewell PA (1992) Extraction of lipids and derivative formation. In Lipid Analysis. A Practical Approach, pp. 13-64 [RJ Hamilton and S Hamilton, editors]. Oxford: IRL Press.

41. Jakobsen J, Maribo H, Bysted A, et al. (2007) 25-Hydroxyvitamin $D_{3}$ affects vitamin $D$ status similar to vitamin $D_{3}$ in pigs - but the meat produced has a lower content of vitamin D. Br J Nutr 98, 908-913.

42. Jakobsen J, Clausen I, Leth T, et al. (2004) A new method for the determination of vitamin $\mathrm{D}_{3}$ and 25-hydroxyvitamin $\mathrm{D}_{3}$ in meat. J Food Comp Anal 17, 777-787.

43. Folch J, Lees M \& Sloane Stanley GH (1957) A simple method for the isolation and purification of total lipids from animal tissues. J Biol Chem 226, 497-509.

44. Damsgaard CT, Schack-Nielsen L, Michaelsen KF, et al. (2006) Fish oil affects blood pressure and the plasma lipid profile in healthy Danish infants. $J$ Nutr 136, 94-99.

45. Wagner D, Hanwell HE \& Vieth R (2009) An evaluation of automated methods for measurement of serum 25-hydroxyvitamin D. Clin Biochem 42, 1549-1556.
46. Friedewald WT, Fredrick DS \& Levy RI (1972) Estimation of concentration of low-density lipoprotein cholesterol in plasma, without use of preparative ultracentrifuge. Clin Chem 18, 499.

47. Matthews DR, Hosker JP, Rudenski AS, et al. (1985) Homeostasis model assessment - insulin resistance and beta-cell function from fasting plasma-glucose and insulin concentrations in man. Diabetologia 28, 412-419.

48. Nichols WW \& O'Rourke M (2005) McDonald's Blood Flow in Arteries - Theoretical, Experimental and Clinical Principles, 5th ed. New York: Oxford University Press, Inc.

49. Hooper L, Thompson RL, Harrison RA, et al. (2004) Omega 3 fatty acids for prevention and treatment of cardiovascular disease. The Cochrane Database of Systematic Reviews CD003177.

50. Kiokias S \& Gordon MH (2003) Dietary supplementation with a natural carotenoid mixture decreases oxidative stress. Eur J Clin Nutr 57, 1135-1140.

51. Lara JJ, Economou M, Wallace AM, et al. (2007) Benefits of salmon eating on traditional and novel vascular risk factors in young, non-obese healthy subjects. Atherosclerosis 193, 213-221.

52. Gunnarsdottir I, Tomasson H, Kiely M, et al. (2008) Inclusion of fish or fish oil in weight-loss diets for young adults: effects on blood lipids. Int J Obes 32, 1105-1112.

53. Elvevoll EO, Barstad H, Breimo ES, et al. (2006) Enhanced incorporation of $n-3$ fatty acids from fish compared with fish oils. Lipids 41, 1109-1114.

54. Vidgren HM, Agren JJ, Schwab U, et al. (1997) Incorporation of $n-3$ fatty acids into plasma lipid fractions, and erythrocyte membranes and platelets during dietary supplementation with fish, fish oil, and docosahexaenoic acid-rich oil among healthy young men. Lipids 32, 697-705.

55. Mozaffarian D \& Rimm EB (2006) Fish intake, contaminants, and human health: evaluating the risks and the benefits. JAMA 296, 1885-1899.

56. Parks EJ \& Hellerstein MK (2000) Carbohydrate-induced hypertriacylglycerolemia: historical perspective and review of biological mechanisms. Am J Clin Nutr 71, 412-433.

57. Fehily AM, Burr ML, Phillips KM, et al. (1983) The effect of fatty fish on plasma-lipid and lipoprotein concentrations. Am $J$ Clin Nutr 38, 349-351.

58. Brown AJ, Roberts DCK, Pritchard JE, et al. (1990) A mixed Australian fish diet and fish oil-supplementation - impact on the plasma lipid profile of healthy men. Am J Clin Nutr 52, $825-833$.

59. Sijben JWC \& Calder PC (2007) Differential immunomodulation with long-chain $n$-3 PUFA in health and chronic disease. Proc Nutr Soc 66, 237-259.

60. Graff IE, Hoie S, Totland GK, et al. (2002) Three different levels of dietary vitamin $\mathrm{D}_{3}$ fed to first-feeding fry of Atlantic salmon (Salmo salar L.): effect on growth, mortality, calcium content and bone formation. Aquacult Nutr 8, 103-111.

61. Mattila P, Piironen V, Hakkarainen T, et al. (1999) Possibilities to raise vitamin $\mathrm{D}$ content of rainbow trout (Oncorhynchus mykiss) by elevated feed cholecalciferol contents. J Sci Food Agric 79, 195-198.

62. Lu Z, Chen TC, Zhang A, et al. (2007) An evaluation of the vitamin $D_{3}$ content in fish: is the vitamin $D$ content adequate to satisfy the dietary requirement for vitamin D? J Steroid Biochem Mol Biol 103, 642-644.

63. Mattila P, Piironen V, Uusi-Rauva E, et al. (1995) Cholecalciferol and 25-hydroxycholecalciferol contents in fish and fish products. J Food Comp Anal 8, 232-243.

64. Cashman KD, Hill TR, Lucey AJ, et al. (2008) Estimation of the dietary requirement for vitamin $\mathrm{D}$ in healthy adults. Am J Clin Nutr 88, 1535-1542. 